Burkitt, E., Barrett, M., \& Davis, A. (2009). Effects of different emotion terms on the size and colour of children's drawings. International Journal of Art Therapy, 14, 74-84.

Effects of different emotion terms on the size and colour of children's drawings

\author{
Esther Burkitt ${ }^{1}$, Martyn Barrett ${ }^{2}$ and Alyson Davis ${ }^{3}$ \\ ${ }^{1}$ Centre for Childhood, Development and Learning \\ The Open University \\ UK \\ $2 \& 3$ Department of Psychology \\ University of Surrey \\ UK
}

Acknowledgements: The research team would like to thank all of the children and teachers who participated in this project. 


\title{
Effects of different emotion terms on the size and colour of children's drawings
}

\begin{abstract}
Recent studies have shown that, when an affective characterisation is given to a topic, children adjust the size and colour of those topics in their drawings: children increase the size of drawings of topics characterised as "nice”, do not always decrease the size of topics characterised as "nasty", and use differential colouring systematically to distinguish between "nice” and "nasty” topics in their drawings (Burkitt, Barrett, Davis, 2003a, 2003b, 2004). The present experiment was designed to examine whether these specific effects only occur with the terms "nice" and nasty", or whether they also occur with another pair of positive and negative terms, "happy” and "sad”. 102 4-7 year olds were divided into two groups and asked to draw either a baseline, "nice” and "nasty" man, or a baseline, "happy” and "sad” man. It was found that the valence of the characterisation (positive vs. negative), as well as the specific pair of words which was used, systematically influenced both the size and the colour of the children's drawings. These results show the importance of understanding the exact emotions in question when interpreting children's drawings on the basis of size and colour.
\end{abstract}


Keywords:

Children, emotion, drawing, interpretation, colour, size

Biographies:

Dr. Esther Burkitt is a lecturer in Developmental Psychology with The Open University and has a keen interest in the development of children's understanding of, and expression through, drawing and a keen interest in research methodologies in this area.

Prof Martyn Barrett is a Professor of Developmental Psychology at the University of Surrey. One of his many interests is in the development of children's drawings, in particular, the cognitive processes underlying drawing production and in the expression of emotions and feelings in children's drawings.

Dr Alison Davis is currently a Reader in Psychology with The University of Surrey. Her main interests lie within Experimental Developmental Psychology, young children's spatial representation and drawing and in the combined areas of children's imagination and pretence.

Word count: 7103 


\section{Introduction}

It has long been argued that children express their feelings about certain topics by altering specific features in their drawings of those topics (Craddick, 1961, 1963; Hammer, 1958, 1997; Koppitz, 1964, 1968; Machover, 1949). More specifically, it has been argued that these alterations vary depending on whether the children regard the topics positively or negatively (Fox \& Thomas, 1990; Thomas, Chaigne \& Fox, 1989). Early research suggested that children often increase the size of positive topics (Craddick, 1961) and reduce the size of negative topics in their drawings (Craddick, 1963; Koppitz, 1966; Machover, 1949), and that colouring is also used by children in their drawings to differentiate between depictions of positive vs. negative topics (Alschuler \& Hattwick, 1943, 1947; Arnheim, 1956, 1974; Golomb, 1981; Hammer, 1953, 1997). However, the majority of these claims have been based either upon experiments with poor methodological controls, or were derived from single case studies in which there were no independent assessments of the affective connotations of the topics being drawn (see Burkitt, Barrett \& Davis, 2003a, 2003b for an extended discussion of these problems).

However, in a series of recent experiments, Burkitt et al. (2003a, 2003b, 2004) employed both rigorous experimental controls and independent manipulations and assessments of the affective connotations of drawn topics. They found that there were systematic differences in the drawings of 4-11-year-old children when the topics which were being drawn were characterised as "nice” vs. "nasty”. In particular, an increase in size was found to occur when topics were characterised as "nice”. Furthermore, this effect occurred not only in a drawing task where a model was provided for the children to copy (Burkitt et al., 2004), but also in a drawing task in which the children were 
asked to draw the "nice” topic in the absence of any model (Burkitt et al., 2004).

However, topics characterised as "nasty" were not always scaled down in size in these two studies. Burkitt et al. (2003a) also found that 4-11-year-old children use their most preferred colours for colouring in "nice” topics, their least preferred colours for colouring in "nasty" topics, and colours rated intermediately for neutral topics. Black tended to be the most frequently chosen colour for "nasty” topics. By contrast, primary colours were predominantly selected for neutral topics, while a wide range of mainly primary and secondary colours were chosen for colouring in topics characterised as "nice".

However, the particular terms which were used through this sequence of experiments were restricted to a single pair of positive and negative terms in the main, namely "nice” and "nasty” with the exception of one study which examined topic specificity and children's use of colour (Burkitt \& Newell, 2005). The question therefore arises as to whether the children in the majority of past experiments were responding to the specific terms "nice" and nasty", or whether the pattern of responding which was displayed is indicative of a more general tendency to respond differentially in their drawings to any positive vs. negative affective characterisation of the topics being drawn. The present experiment used the terms "happy" and "sad", as used in a related project (Burkitt \& Newell, 2005), as a comparison pair to “nice” and "nasty” in order to explore this issue. Because the characteristics of "nice” and "nasty” typically relate to the perception by other people of the depicted figure, whereas the characteristics of "happy" and "sad" relate more to the internal affect state of the figures themselves (as expressed through external signals such as facial expressions), it was judged that this direct comparison would provide an especially robust test of the 
prediction that similar size and colouring effects may occur with any pair of positive vs. negative terms. The use of "happy" and "sad" in the present study was further motivated by the additional consideration that these are particularly important terms to explore from a clinical perspective, given their possible utility in the identification and measurement of childhood depression (cf. Herbert, 1998; Kazdin, 1990).

Professionals continue to use and interpret children's drawings and art work in a variety of settings for various purposes, and the need to develop rigorous research methodologies to assess emotional aspects of children's drawings is currently recognised (Burkitt \& Newell, 2005; Hammer, 1997; Hunsley, Lee, \& Wood, 2003). Drawings are often viewed a means to facilitate emotional expression and communication and are often interpreted in their own right for signs of the artist's emotional adjustment (Hammer, 1997; Silver, \& Carrion, 1991). The proposed research was therefore partly motivated to expand upon existing research by systematically assessing possible differences in children's drawings arising from the particular emotions in question in a specific drawing context.

Previous research into children's recognition of human facial expressions of emotion has found that such recognition improves substantially with age (e.g. Beck \& Feldman, 1989; Camras \& Allison, 1985; Walden \& Field, 1982). However, less attention has been given to children's graphic depictions of emotional expressions such as "happy” and "sad”. The studies that have been conducted exploring drawing production suggest that primary school children possess a restricted graphic repertoire for representing emotional facial expressions. Golomb (1992) studied children’s freehand drawings of "happy”, "sad” and "angry” children, and found that children modified mouths more easily than eyebrows to depict emotions, with younger children 
experiencing difficulty in using oblique lines to depict eyebrows on "angry” faces. In addition, it has been found that children’s ability to produce and decode facial emotions (of happiness, sadness, fear and disgust) in their own drawings improves with age, and that children are better at decoding their own drawings of "happy” and "sad”, rather than "fearful” and “disgusted”, faces (Lakshman \& Whissell, 1991). Sayil (1996) investigated 4-6-year-old children’s production and recognition of "happy”, "sad”, “surprised” and “angry” faces using facial completion drawing tasks, matcheddiscrimination tasks, and forced-choice labelling tasks. She found that whilst young children could recognise the range of emotions in the matched-discrimination tasks, they were unable to differentiate emotional facial features within their own drawings. This ability was observed to improve with age. Children were more successful at drawing "happy” and "sad” faces compared with "angry” and "surprised” faces in their freehand drawings. A comparable study with older primary school children (Sayil, 1998) revealed that all age groups from grades 1 to 5 could draw "happy” features on pre-drawn face outlines, with the ability to produce "sad”, “angry” and "surprised” faces developing more slowly with age. It should be noted that Sayil's studies examined facial expressions, not the depiction of the entire figure (unlike the present study).

Children’s ability to produce "happy” and "sad” human figures has been extended to other topics. Ives (1984) asked children aged 4 to 16 years to draw "happy”, “sad”, “angry”, “quiet”, “loud” and "hard” trees and lines. The drawings were categorised according to the use of literal, abstract and content strategies, and it was found that younger children employed more literal features, such as drawing tears on trees to represent sadness, whilst the older children adopted abstract strategies, such as downward lines to indicate sad trees. This trend was replicated by Winston, Kenyon, 
Stewardson \& Lepine (1995), who found that the quality and quantity of expressive strategies when drawing emotive scenes, such as representing themes of ageing, developed with age. The relationship between children’s metaphorical awareness and ability to produce abstract metaphorical symbols to express mood has been well documented (e.g. Carothers \& Gardner, 1979; Jolley \& Thomas, 1995; Jolley, Zhi \& Thomas, 1998). These studies indicate that whilst children can understand metaphorical expressive features in drawings, they are more likely to represent mood using literal properties in their own drawings.

In contrast to these previous studies, the present study was designed to explore whether children use size and colour in their drawings systematically to differentiate between "happy" and "sad" figures in a similar way to how they use these features to differentiate between "nice” and "nasty” figures in their drawings.

\section{Method}

Participants

102 children (53 boys and 49 girls) aged between 4 years 3 months and 7 years 6 months participated in the experiment. The children were divided into two age groups, and the children within each age group were randomly allocated to one of two condition groups, either a nice/nasty group (henceforward NN) or a happy/sad group (henceforward HS). The mean age of the young age group $(\mathrm{N}=51)$ was 5 years 1 month (range: 4 years 3 months to 5 years 11 months) while the mean age of the old age group $(\mathrm{N}=51)$ was 6 years 9 months (range: 6 years 0 months to 7 years 6 months).

\section{Materials}


10 colour cards (red, orange, yellow, green, blue, purple, pink, white, brown and black), 10 crayons of the same selection of colours as the cards, A4 plain white paper, and lead pencils were used. A five-point smiley-face Likert scale (showing faces with very unhappy, unhappy, neither unhappy nor happy, happy, and very happy expressions) was used to gather affect ratings towards each individual colour in Session 1, and to gather affect ratings towards the completed drawings in Session 2.

Procedure

All children completed two test sessions. The two sessions were presented in counterbalanced order to control for possible order effects. Children were seen individually in a quiet area of their school for both sessions, which were always conducted on two successive days.

\section{Session 1}

In Session 1, all children completed a colour preference task. The children were shown the ten colour cards in a random order. As each colour was presented, they were asked to rate how the colour made them feel, using the 5-point Likert scale. Responses were scored between 1 and 5, with 1 = "very unhappy” and 5 = "very happy”. The instructions were as follows: "I would like to find out how you feel about this colour. What I'd like you to do is point to the face to show how you feel about the colour. Here are the faces that you are going to be looking at (pointing to each face). The first one is a very unhappy face; the next one is quite an unhappy face; the middle one is neither happy nor unhappy. The fourth face is quite a happy face and the last one is a very happy face. When you answer my question, I'd like you to point to the face that 
describes how you feel about the colour. OK?" The instructions were repeated in full if the child indicated that they had not understood. Few children required additional prompting.

\section{Session 2}

In session 2, children drew three pictures of a man. All children first drew a baseline, affectively uncharacterised, figure. They then drew two affectively characterised figures in counterbalanced order; children in the NN group drew a "nice" and a "nasty" figure, while children in the HS group drew a "happy" and a "sad" figure. Immediately after drawing each individual figure, the child was asked to rate how he/she felt about the drawn figure by pointing to the appropriate face on the Likert scale. Responses were again scored between 1 and 5, with $1=$ "very unhappy" and $5=$ "very happy". The drawing was then removed, and the child was given a fresh sheet of A4 paper for the production of the next drawing. The same range of crayons and the pencil were left in place throughout the session.

Children in both groups were asked to draw a baseline, neutrally characterised, figure using the following instructions: "I'd like you to draw a man. Use the pencil to draw him, and just one of these colours to colour him in. Draw the whole man as well as you can and colour him in as well as you can”.

Children in the NN group were then asked to draw a nice and a nasty figure (in counterbalanced order), using the following instructions. Nice figure: “Now, think of a man who is a very kind nice man, and who is very pleasant and friendly to everyone. Draw the man, remembering what a nice person he is. Use the pencil to draw him, and just one of these colours to colour him in. Draw the whole man as well as you can and 
colour him in as well as you can." Nasty figure: "Now, think of a man who is a very nasty horrible man who is very mean and unfriendly to everyone. Draw the man, remembering what a nasty man he is. Use the pencil to draw him, and just one of these colours to colour him in. Draw the whole man as well as you can and colour him in as well as you can”.

Children in the HS group were asked to draw a happy and a sad figure (in counterbalanced order), using the following instructions. Happy figure: “Now, think of a man who is a very very happy man, and who is very pleasant and friendly to everyone. Draw the man, remembering what a happy person he is. Use the pencil to draw him, and just one of these colours to colour him in. Draw the whole man as well as you can and colour him in as well as you can". Sad figure: "Now, think of a man who is a very very sad man, and who is very mean and unfriendly to everyone. Draw the man, remembering what a sad man he is. Use the pencil to draw him, and just one of these colours to colour him in. Draw the whole man as well as you can and colour him in as well as you can”.

Drawing ability

During the test period, class teachers were asked to rate each child's drawing ability relative to a typical year group member's ability using the following question: “Thinking of a typical Year \{Year group of child\}, please rate \{child's name\} drawing ability on the following scale: poor (1), below average (2), average (3), above average (4), good (5).”

Measurements 
The height of each drawing was measured as the vertical distance from the top to the lowest extremity of the outlines drawn in lead pencil. Width was measured as the horizontal distance between the farthest left and right extremities of the lead pencil outline of the figure. Surface area was measured using 0.5 centimetre squares. Squares with greater than 50\% covered were included, and squares with less than $50 \%$ coverage were excluded. A second judge measured the surface area of all of the drawings from each age group. 97\% inter-judge reliability was obtained. Discrepancies were resolved by recounting by both judges, and all drawings were included in the analysis.

Results

All children successfully completed the range of tasks. Drawing ability was first analysed using a 2 (age group) x 2 (NN vs. HS) ANOVA, and no main or interaction effects were found. This variable was therefore excluded from further analysis. The data were also screened for potential order of counterbalancing effects, and none were found. Thus, order of counterbalancing was also excluded from the following analyses.

Surface area

**INSERT TABLE 1 ABOUT HERE**

A 2 (age group) x 2 (NN vs. HS) x 3 (drawing type: baseline vs. positive vs. negative) three-way mixed ANOVA was conducted on surface area scores, with drawing type entered as the repeated measure, and independent groups on the other two factors. A main effect was found for drawing type $(F(2,196)=16.36, p<0.01)$, with high power and a large effect size $\left(\mathrm{P}=1.00\right.$, eta $\left.^{2}=0.14\right)$. Post hoc paired t-tests $(\mathrm{p}<0.05)$ on the means in Table 1 revealed that the positive drawings were larger than both the 
baseline and negative drawings, and that the negative drawings were also larger than the baseline drawings. However, an interaction effect was also found between drawing type and group $(\mathrm{F}(2,196)=5.32, \mathrm{p}<0.05)$. High power was observed for this large effect $(\mathrm{P}=$ 0.84, eta $\left.{ }^{2}=0.15\right)$ Post hoc paired and independent t-tests $(\mathrm{p}<0.05)$ revealed that the NN group drew both "nice” and "nasty” men larger than baseline men, whereas the HS group drew the "happy” men larger than the baseline men, and drew the "happy” men larger than the "sad” men. There was no significant difference between baseline drawing surface area between the two groups. A main effect was also found for group $(F(1,98)=15.80, p<0.01)$, with the NN group drawing larger men than the HS group overall. Observed power was high for this large effect $\left(\mathrm{P}=0.98\right.$, eta $\left.^{2}=0.14\right)$. No other significant effects were found.

Height

A 2 (age group) x 2 (NN vs. HS) x 3 (drawing type) three-way mixed ANOVA was also conducted on the height scores. A main effect was found for drawing type $(F(2,196)=20.42, p<0.01)$. High observed power was seen for this large effect $(P=1.00$, eta $\left.^{2}=0.18\right)$. Post hoc paired t-tests $(\mathrm{p}<0.05)$ indicated that positive drawings $(\mathrm{M}=$ 15.38, $\mathrm{SD}=6.89)$ were taller than both the baseline $(\mathrm{M}=10.96, \mathrm{SD}=5.61)$ and the negative $(M=13.25$, $S D=6.88)$ drawings, and negative drawings were taller than the baseline drawings. No further main or interaction effects were found.

Width

A 2 (age group) x 2 (NN vs. HS) x 3 (drawing type) three-way mixed ANOVA was conducted on the width scores. A main effect was found for drawing type 
$(\mathrm{F}(2,196)=22.14, \mathrm{p}<0.01)$, with a small effect size with high observed power $(\mathrm{P}=1.00$, eta $\left.^{2}=0.02\right)$. Post hoc paired t-tests $(\mathrm{p}<0.05)$ revealed that the positive drawings $(\mathrm{M}=$ 9.38, $\mathrm{SD}=4.28)$ were wider than both the baseline $(\mathrm{M}=6.69, \mathrm{SD}=3.69)$ and negative $(\mathrm{M}=7.95, \mathrm{SD}=4.72)$ drawings, and that the negative drawings were wider than the baseline drawings. A main effect was also found for age group $(F(1,98)=4.40, p<0.05)$, with high power and a small effect size $\left(\mathrm{P}=1.00\right.$ eta $\left.^{2}=0.03\right)$. The younger age group $(M=8.50, S D=3.76)$ produced wider drawings than the older age group $(M=7.52, S D$ = 3.20). No other significant effects were found.

Affect towards neutrally, positively and negatively characterised figures

\section{**INSERT TABLE 2 ABOUT HERE**}

The affect ratings from the Likert scale towards the three drawn figures that were produced in Session 2 were examined to investigate whether the children had assigned different affect to the differently characterised figures. A 2 (age group) x 2 (NN vs. HS) x 3 (drawing type) three-way mixed ANOVA revealed a main effect of drawing type $(\mathrm{F}(2,196)=372.07, \mathrm{p}<0.01)$. The effect size was large with high power $\left(\mathrm{P}=1.00\right.$, eta $\left.^{2}=0.80\right)$ Post hoc paired t-tests $(\mathrm{p}<0.05)$ on the means shown in Table 2 revealed that the positive drawings were given more positive ratings than both the baseline and negative drawings, and the baseline drawings were given more positive ratings than the negative drawings. Hence, the children did indeed rate the figures as anticipated, in the expected directions.

In addition, a main effect of NN vs. HS was also found $(F(1,98)=14.91, p<0.01)$, with the NN group giving more positive ratings than the HS group overall. The effect size was moderate with high observed power $\left(\mathrm{P}=0.97\right.$, eta $\left.^{2}=0.13\right)$. However, this effect 
was qualified by a significant interaction between drawing type and NN vs. HS

$(F(2,188)=5.97, p<0.05)$, with a moderate effect size and high observed power $(\mathrm{P}=0.91$, eta $\left.^{2}=0.07\right)$. Post hoc independent t-tests $(\mathrm{p}<0.05)$ showed that the NN group rated the baseline drawings more positively than the HS group, whereas there were no significant differences in the NN and HS groups' ratings of the positive and negative figures (see Table 2).

Affect towards the colours chosen for the three drawing types

The ratings from the Likert scale gathered in Session 1 towards the particular colours which the children had used to complete the three drawings in Session 2 were used to explore whether the children had systematically used differentially liked colours for the three different drawing types. A 2 (age group) x 2 (NN vs. HS) x 3 (drawing type) three-way mixed ANOVA revealed a main effect of drawing type $(\mathrm{F}(2,188)=74.30, \mathrm{p}<0.01)$. The effect was large with high observed power $\left(\mathrm{P}=1.00\right.$, eta $^{2}$ $=0.44)$. Post hoc paired t-tests $(\mathrm{p}<0.05)$ revealed that the children had assigned more positive ratings to the colours used for the positive drawings $(\mathrm{M}=4.51, \mathrm{SD}=1.01)$ than those used for the baseline $(M=3.78, S D=1.30)$ and negative $(M=2.51, S D=1.58)$ drawings, and had assigned more positive ratings to the colours used for the baseline drawings than those used for the negative drawings. A main effect was also found for NN vs. HS $(F(1,94)=6.81, p<0.05)$, with a moderate effect size and fairly high observed power $\left(\mathrm{P}=0.77\right.$, eta $\left.{ }^{2}=0.07\right)$. The HS group $(\mathrm{M}=3.77, \mathrm{SD}=0.79)$ gave more positive affect ratings to the colours which had been used in their drawings than the NN group $(\mathrm{M}=3.28, \mathrm{SD}=0.97)$ overall. No other main or interaction effects were found. 
Children's colour choices for the three drawing tasks

Frequency counts of the specific colours which had been used for the three drawing types (baseline, positive and negative) were made. These frequencies were analysed using correspondence analysis, in order to explore the specific colours which had been used for the different drawings by different subgroups. Correspondence analysis (Hammond, 1988, 1993) uses geometric principles to provide a pictorial representation of the relationship between categories of response and groups of individuals. It permits a multi-dimensional analysis of categorical data by providing a plot in which the geometric distance between the groups and the types of response gives a direct measure of the relative degree of association between the groups and the response types. These plots therefore reveal those colour choices which are most closely associated with each individual subgroup (be this drawing type, NN vs. HS, or age group) and which therefore best discriminate the behaviour of the children within each subgroup.

A series of individual correspondence analyses was run. Colours with a response frequency count of less than 5 were not included in these analyses to avoid the results being biased by these low frequency responses (Hammond, 1988). In the first set of analyses, the particular colours which had been used for the three drawing types were analysed for the NN and HS groups separately. In the second set of analyses, the colours that had been used by the NN vs. HS groups were analysed for each individual drawing type separately (to directly compare the colour choices made by the two groups of children on each type of drawing). Finally, the colour choices of the younger age group were compared with those of the older age group; however, this third set of analyses failed to reveal any significant associations with age. 
**INSERT PLOTS 1, 2 AND 3 ABOUT HERE**

Plot 1: Colour choices for each drawing type by the NN group

The colour choices of the children in the NN group were analysed across drawing type, and one significant dimension was found $\left(\chi^{2}(8)=19.48, \mathrm{p}<0.01\right)$. Plot 1 shows that blue, yellow, pink, red and purple were more closely associated with the baseline and "nice" men than with the "nasty" men, and black and brown were more closely associated with the "nasty" men rather than with the baseline or "nice" men.

Plot 2: Colour choices for each drawing type by the HS group

Two significant dimensions were found for the colour choices of the children in the HS group $\left(\chi^{2}(10)=29.02, \mathrm{p}<0.01 ; \chi^{2}(8)=15.75, \mathrm{p}<0.05\right)$. Red, pink and green were most closely associated with baseline drawings; orange, purple and yellow were most closely associated with the "happy” drawings; and black was most closely associated with the "sad" drawings (see Plot 2).

Plot 3: Colour choices for the negative figures by the NN vs. HS groups

Analyses were also run on each drawing type individually, directly comparing the NN and HS colour choices for each type. No significant differences emerged between the two groups on the colours that had been used for the baseline and positive drawing types. However, for the negative figures, two significant dimensions were found $\left(\chi^{2}(10)=35.65, \mathrm{p}<0.01 ; \chi^{2}(8)=16.95, \mathrm{p}<0.05\right)$. Plot 3 reveals that black was more closely associated with the NN group than with the HS group, and red and purple were more closely associated with the HS group. 


\section{Discussion}

Size

This study shows that the particular emotion terms used to describe a human figure ("nice” vs. "happy”, "nasty” vs. "sad”), as well as the valence of the affective characterisation (i.e. positive vs. negative), can influence the size of children's human figure drawings. Children drawing "nice” and "happy” men systematically drew larger figures than those drawing "nasty” and "sad” men. However, in addition, children drawing "nice” and "nasty” men (NN group) produced larger drawings overall than the children producing "happy” and "sad” men (HS group). It should be noted that a supplementary content analysis of the children's use of additional details to depict the characteristics of the figures in their drawings did not reveal any group differences. Hence, the differential sizes of the four types of figure were not attributable to the inclusion of a greater number of details in the larger figures (Freeman, 1980).

It might be argued that children drawing the "nice” and "nasty” men exhibited more positive affect overall towards their three drawings than the children drawing the "happy" and "sad" men, and this could therefore be the factor responsible for the differential figure sizes between the two groups. However, although children in the NN group did indeed exhibit higher positive affect towards the figures than the HS group

overall, this trend was primarily due to the differential levels of affect displayed towards the baseline figures across the two groups, rather than the levels of affect which were displayed towards the affectively characterised figures (see Table 2). Hence it is unlikely that differential levels of affect were responsible for the dramatically larger sizes of the "nice” and "nasty” figures compared with the "happy" and "sad” figures (see Table 1). 
An alternative possible explanation of the much larger size of the drawings produced by the NN group is that children are better able to depict the characteristics of "happy" and "sad" than the characteristics of "nice” and "nasty” because they have better developed planning and motor skills for graphically representing the former pair. It is known that children are more successful with encoding "happy" and "sad" in their drawings than other less basic emotions such as “anger” and “disgust” (Golomb, 1992; Ives, 1984; Sayil, 1996, 1998). Hence, the differential sizes used for "happy" and "sad” vs. "nice” and "nasty" might reflect differences in the children's ability to graphically encode and produce these two different sets of characterisations (Cleeve \& Bradbury, 1992; Fox \& Thomas, 1990; Jolley, 1995; Thomas et al., 1989). In other words, children may be more familiar with drawing "happy” and "sad” figures than "nice” and "nasty" figures, the former therefore relying on better-rehearsed drawing schemata.

That said, for both groups of children (and consistent with previous research, e.g. Burkitt et al., in press, submitted; Thomas et al., 1989), positively characterised figures were drawn larger, wider and taller than baseline figures, whereas negatively characterised figures were not reduced in size from baseline figure size. This study therefore provides further empirical support for the generalisability of the previously documented size effects across an additional set of positive and negative terms. This is in addition to our knowledge that these effects also occur across different drawing topics (Burkitt et al. (2003a, 2003b, 2004) found that these effects occur not only in children's human figure drawing but also in their drawings of dogs and trees). Furthermore, these findings once again confirm that size effects are more consistent for positively characterised figures than for negatively characterised figures, with positively 
characterised men consistently being increased in size from baseline drawing size, and negatively characterised men not always being reduced from baseline drawing size.

Also in line with previous findings, few age differences were uncovered in the present study. The only age effect that was found consisted of the younger children producing wider drawings overall than the older children (which in itself is not surprising, given the literature attesting to children human figure drawing becoming smaller with age due to increased planning and motor skills: see Cox, 1992; Freeman, 1980). Presumably comparable age effects did not occur with surface area and height because of the tightly constrained experimental conditions which were employed in this study.

This study also shows that children's sensitivity to the demand to portray a binary contrast specified in the verbal instructions is not, on its own, a sufficient explanation of why size effects occur in children's drawings. While some aspects of children's drawings may indeed be influenced merely by the provision of a single contrast (Cox, 1981, 1985; Chen \& Holman, 1989; Davis, 1983, 1985a, 1985b; Lewis, Russell \& Berridge, 1993), the present study clearly shows that the children marked "nice” and "happy” differently in their drawings, and "nasty” and "sad” differently, implying that they were responding on the basis of the specific emotion terms provided, not merely to the provision of a binary contrast per se.

In considering whether children might be responding to the positive and negative characterisations on the basis of an acquired pictorial convention or an appetitive-defensive mechanism (see Burkitt et al., 2004, for a discussion of these two possibilities), it would appear that the data do not actually support either of these two interpretations. If children were operating using a pictorial convention that "nice" 
figures should be drawn larger than "nasty” figures, then age differences would have been expected as a consequence of the progressive acquisition of this convention with age (unless the acquisition process itself is complete by the age of four, which is not very plausible); however, no such age effects were found. Alternatively, if an appetitive-defensive mechanism were to be responsible for these effects, then it would be predicted that “nasty” drawings would be drawn smaller than "sad” drawings, as nastiness signals a greater level of potential threat than sadness. However, this effect was also not found. Hence, while size changes clearly do occur in children’s drawings, the present set of findings does not actually support either of the two existing theories which have been proposed to explain these effects.

Colour

Children in both the NN and the HS groups affectively rated the colours which they used in their positive drawings more positively than the colours which they used in their baseline drawings, and the colours used in their baseline drawings more positively than the colours used in their negative drawings. There was no evidence of any agerelated trends in children's use of colour in this study. All of these findings are consistent with previous findings (Burkitt et al., 2003a, 2003b, 2004; Burkitt \& Newell, 2005), but additionally demonstrate the reliability of recent claims that colour effects do not only occur with the terms “nice” and "nasty” (Burkitt \& Newell, 2005).

Examination of the particular colours which children chose for the three drawing types revealed differences between the two groups. For the NN group, blue, yellow, pink, red and purple were associated with the baseline and "nice” drawings, and black and brown for the "nasty” drawings. However, for the HS group, children’s colour 
choices for baseline and "happy" men were more clearly discriminated from each other. Red, pink and green were more closely associated with the baseline rather than the "happy” figure. Orange, purple and yellow were associated with the "happy” drawings. This is consistent with trends noted in previous studies (e.g. Alschuler \& Hattwick, 1943, 1947; Brick, 1944; Winston et al., 1995). It could be that the use of "happy” as opposed to "nice" for the positive emotion term inspired a more discriminating response of colour associations from baseline colour choices. One possible explanation for this effect is that children are more familiar with the terms of "happy” and "sad” being applied to colours than the terms of "nice” and "nasty”. These effects have been found when children are not restricted to using only symbolic colours (Winston et al., 1995), implying that even young children are indeed sensitive to the symbolic associations of colours.

Black was the principal colour used for the drawings of "sad" men, and black and brown for the "nasty” men. In other words, this study confirmed that children do tend to use darker colours for negative topics (as previously found by Burkitt et al., 2003) and these darker colours are typically rated as the children’s least preferred colours overall. It has frequently been argued in the clinical literature that darker colours tend to be used to a greater extent by individuals who are less well emotionally adjusted, and for the depiction of negative topics (Alschuler \& Hattwick, 1943, 1947; Brick, 1944; Miljkovitch de Heredia \& Miljkovitch, 1998; Waehner, 1946). The present study provides further support for the idea that black and brown are indeed more closely associated with the depiction of negative topics.

Once again, it is not entirely clear why children come to associate different colours with positive or negative topics. One possibility is that children acquire these 
associations from the pictorial conventions which are used in colouring books and other media. This explanation has been suggested as the mechanism which is responsible for children's associations of particular colours with facial expressions of emotions (Zentner, 2001). The same explanation might also account for why children come to use colours differentially when drawing emotion-eliciting topics.

Whilst the specific context of the production of the drawings in the present study needs to be borne in mind when assessing the generalisability of the present findings, the present research does suggest that children display a graphic flexibility when depicting specific positive and negative emotions. The applied value of this work would be enhanced by gathering drawings in more naturalistic clinical and therapeutic settings where different emotions may be influential in shaping the specific features and formal properties of children's drawings. The features of the present research design could be easily modified for such applied research.

In conclusion, this study has shown that children used both size and colour differentially in their drawings to represent positively and negatively characterised topics. These effects occur not only occur with the terms "nice” and "nasty”, but also with the terms "happy" and "sad”. However, these effects do differ depending upon the precise terms which are used. Future studies will need to investigate the impact of other sets of contrasting emotion terms, and will also need to assess children's use of colour combinations, given that in the present and previous studies the children have been limited to using just a single colour. Further manipulations of the specific positive and negative terms which are used, in conjunction with the use of multiple colours, could be an especially interesting avenue to explore, especially if the findings are to be of 
relevance to the clinical assessment of the child in situations where colour use may not be restricted to the use of a single colour. 


\section{References}

Alschuler, R., \& Hattwick, L. A. (1943). Easel painting as an index of personality in pre-school children. Journal of Orthopsychiatry, 13, 616-625.

Alschuler, R., \& Hattwick, L. A. (1947). Painting and Personality. Volumes I and II. Chicago: The University of Chicago Press.

Arnheim, R. (1956). Art and Visual Perception: A Psychology of the Creative Eye. London: Faber \& Faber.

Arnheim, R. (1974). Art and Visual Perception: A Psychology of the Creative Eye. The New Version. Berkeley, CA: University of California Press.

Beck, L. \& Feldman, R. S. (1989). Enhancing children’s decoding of facial expression. Journal of Nonverbal Behavior, 13, 269-278.

Brick, M. (1944). The mental hygiene value of children's art work. American Journal of Orthopsychiatry, 14, 136-146.

Burkitt, E., Barrett, M. \& Davis, A. (2003a). Children’s colour choices for completing drawings of affectively characterised topics. Journal of Child Psychology and Psychiatry, 44, 3, 445-455. 
Burkitt, E., Barrett, M. \& Davis, A. (2003b). The effect of affective characterisations on the size of children's drawings. British Journal of Developmental Psychology, 21, 565584.

Burkitt, E., Barrett, M. \& Davis, A. (2004). The effects of affective characterisations on the use of size and colour in drawings produced by children in the absence of a model. Educational Psychology, 24, 3, 315-343.

Burkitt, E. \& Newell, T. (2005). The impact of topic specificity on children's depiction of emotional traits. International Journal of Art Therapy: Inscape, 10, 1, 15-22

Camras, L. \& Allison, K. (1985). Children’s understanding of facial expressions and verbal labels. Journal of Nonverbal Behavior, 9, 84-94.

Carothers, T. \& Gardner, H. (1979). When children’s drawings become art: The emergence of aesthetic production and perception. Developmental Psychology, 15, 570580.

Chen, M. J. \& Holman, J. (1989). Emergence of drawing devices for total and partial occlusions: A longitudinal study. Perception, 18, 445-455.

Cleeve, H. \& Bradbury, R. J. (1992). Children's productions and judgements of drawings of people of different importance. Poster presented at the 5th European Conference of Developmental Psychology, Seville, September. 
Cox, M. (1981). One thing behind another: Problems of representation in children's drawings. Educational Psychology, 1, 275-287.

Cox, M. (1985). One object behind another: Young children's use of array-specific or view-specific representation. In N. H. Freeman \& M. V. Cox (Eds.), Visual Order: The Nature and Development of Pictorial Representation, pp. 188-200. Cambridge: Cambridge University Press.

Cox, M. (1992). Children’s Drawings. Harmondsworth: Penguin.

Craddick, R. (1961). Size of Santa Claus drawings as a function of time before and after Christmas. Journal of Psychological Studies, 12, 121-125.

Craddick, R. A. (1963). Size of Hallowe’en witch drawings prior to, on and after Hallowe’en. Perceptual and Motor Skills, 16, 235-238.

Davis, A. (1983). Contextual sensitivity in young children's drawings. Journal of Experimental Child Psychology, 35, 478-486.

Davis, A. (1985a). Conflict between canonicality and array-specificity in young children’s drawings. British Journal of Developmental Psychology, 3, 363-372.

Davis, A. (1985b). The canonical bias: young children's drawings of familiar objects. In N. H. Freeman \& M. V. Cox (Eds.), Visual Order: The Nature and Development of Pictorial Representation, pp. 202-213. Cambridge: Cambridge University Press.

Fox, T. \& Thomas, G. (1990). Children's drawings of an anxiety-eliciting topic: Effect on size of the drawing. British Journal of Clinical Psychology, 29, 71-81. 
Freeman, N. H. (1980). Strategies of Representation in Young Children: Analysis of Spatial Skills and Drawing Processes. London: Academic Press.

Golomb, C. (1981). Representation and reality: The origins and determinants of young children’s drawings. Review of Research in Visual Art Education, 14, 36-48.

Golomb, C. (1992). The Child's Creation of a Pictorial World. Berkeley: University of California Press.

Hammer, E. (1953). Frustration-aggression hypothesis extended to socio-racial areas: Comparison of Negro and white children's H-T-P’s. Psychiatric Quarterly, 27, 597607.

Hammer, E. (1958). The Clinical Application of Projective Drawings. Springfield, Ills.: C. C. Thomas.

Hammer, E. (1997). Advances in Projective Drawing Interpretation. Springfield, Ills.: C. C. Thomas.

Herbert, M. (1998). Clinical Child Psychology: Social Learning, Development and Behaviour ( $2^{\text {nd }}$ edition). Chichester: John Wiley.

Hunsley, J., Lee, C. M., \& Wood, J. M. (2003). Controversial and questionable assessment techniques. In S. O. Lilienfeld, S.J. Lynn \& J. M. Lohr (Eds.), Science and Pseudoscience in Clinical Psychology (pp. 39-76). New York: Guilford Press.

Ives, S. (1984). The development of expressivity in drawing. British Journal of Educational Psychology, 54, 152-159. 
Jolley, R. (1995). Children's production and perception of visual metaphors for mood and emotion in line drawings and in art. Unpublished doctoral thesis. University of Birmingham, Birmingham.

Jolley, R. \& Thomas, G. (1995). Children's sensitivity to metaphorical expression of mood in line drawings. British Journal of Developmental Psychology, 13, 335-346.

Jolley, R., Zhi, Z. \& Thomas, G. (1998). The development of understanding of moods metaphorically expressed in pictures: A cross-cultural comparison. Journal of CrossCultural Psychology, 29, 358-376.

Kazdin, A.E. (1990). Childhood depression. Journal of Child Psychology and Psychiatry, 31, 121-160.

Koppitz, E. M. (1966). Emotional indicators on human figure drawings of shy and aggressive children. Journal of Clinical Psychology, 22, 466-469.

Koppitz, E. M. (1968). Psychological Evaluation of Children's Human Figure Drawings. London: Grune and Stratton.

Lakshman, M. \& Whissell, C. (1991). Children's understanding of facial expression of emotion II. Drawing of emotion faces. Perceptual and Motor Skills, 72, 1228-1230.

Lewis, C., Russell, C. \& Berridge, D. (1993). When is a mug not a mug? Effects of content, naming, and instructions on children's drawings. Journal of Experimental Child Psychology, 56, 291-302.

Machover, K. (1949). Personality Projection in the Drawings of the Human Figure. Springfield, IL: C. C. Thomas. 
Miljkovitch de Heredia, R. \& Miljkovitch, I. (1998). Drawings of depressed inpatients: Intentional and unintentional expression of emotion states. Journal of Clinical Psychology, 54, 1029-1042.

Sayil, M. (1996). Preschool children's understanding and drawing of facial expression of emotions. Turkish Journal of Psychology, 11, 61-71.

Sayil, M. (1998). The development of emotional facial drawings in children. Journal of Child and Adolescence Mental Health, 4, 129-133.

Silver, R. A. \& Carrion, F. (1991). Using the Silver drawing test in school and hospital. American Journal of Art Therapy, 30, 36-43

Thomas, G., Chaigne, E. \& Fox, T. (1989). Children’s drawings of topics differing in significance: Effects on size of drawing. British Journal of Developmental Psychology, 7, 321-331.

Waehner, T. (1946). Interpretations of spontaneous drawings and paintings. Genetic Psychology Monographs, 33, 70.

Walden, T. \& Field, T. (1982). Discrimination of facial expression by preschool children. Child Development, 53, 1312-1319.

Winston, A., Kenyon, B., Stewardson, J. \& Lepine, T. (1995). Children’s sensitivity to expression of emotion in drawings. Visual Arts Research, 21, 1-14.

Zentner, M. (2001). Preferences for colours and colour-emotion combinations in early childhood. Developmental Science, 4, 389-398. 
Table 1: Mean surface area $\left(\mathrm{cm}^{2}\right)$ for each drawing type for each group.

\begin{tabular}{|c|c|c|c|c|}
\hline Group & & Drawing Type & & \\
\hline & Baseline & Positive & Negative & Grand Means \\
\hline$N N$ & 27.51 & 68.50 & 61.79 & 52.60 \\
& $(\mathrm{SD}=34.27)$ & $(\mathrm{SD}=68.21)$ & $(\mathrm{SD}=78.55)$ & $(\mathrm{SD}=48.24)$ \\
\hline HS & 18.39 & 35.67 & 20.25 & 24.77 \\
& $(\mathrm{SD}=22.25)$ & $(\mathrm{SD}=40.99)$ & $(\mathrm{SD}=20.23)$ & $(\mathrm{SD}=22.22)$ \\
\hline Grand Means & 21.61 & 47.25 & 34.91 & \\
& $(\mathrm{SD}=27.29)$ & $(\mathrm{SD}=54.24)$ & $(\mathrm{SD}=52.91)$ & \\
\hline
\end{tabular}


Table 2: Mean affect ratings for each drawing type for each group.

\begin{tabular}{|c|c|c|c|c|}
\hline Group & & Drawing Type & & \\
\hline & Baseline & Positive & Negative & Grand Means \\
\hline NN & 3.75 & 4.67 & 1.25 & 3.22 \\
& $(\mathrm{SD}=0.80)$ & $(\mathrm{SD}=0.84)$ & $(\mathrm{SD}=0.44)$ & $(\mathrm{SD}=0.41)$ \\
\hline HS & 2.93 & 4.36 & 1.31 & 2.87 \\
& $(\mathrm{SD}=0.99)$ & $(\mathrm{SD}=0.97)$ & $(\mathrm{SD}=0.64)$ & $(\mathrm{SD}=0.44)$ \\
\hline Grand Means & 3.23 & 4.47 & 1.29 & 2.99 \\
& $(\mathrm{SD}=1.00)$ & $(\mathrm{SD}=0.84)$ & $(\mathrm{SD}=0.57)$ & $(\mathrm{SD}=0.46)$ \\
\hline
\end{tabular}




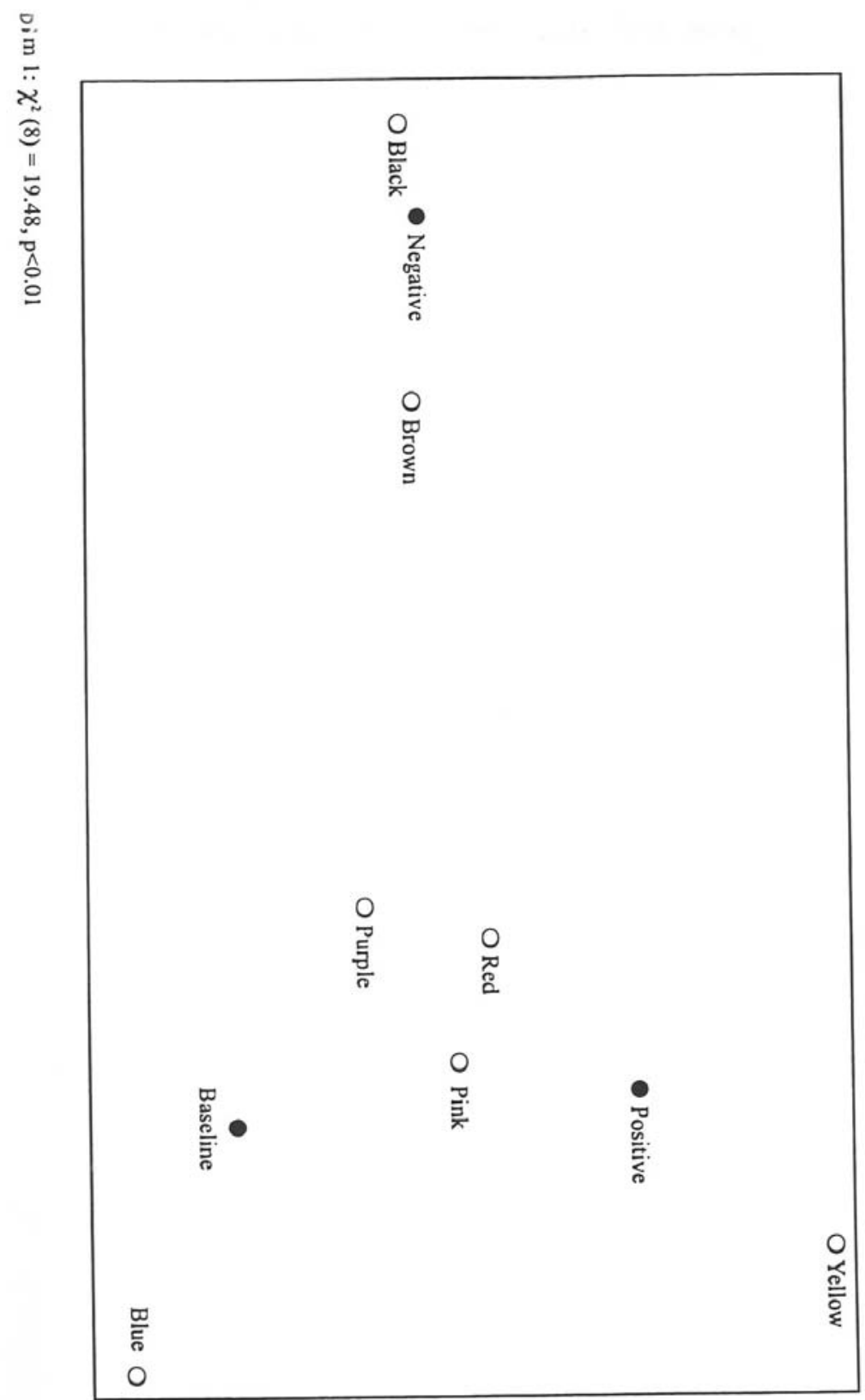

Plot 1: Colour choices for each drawing type by the NN group. 


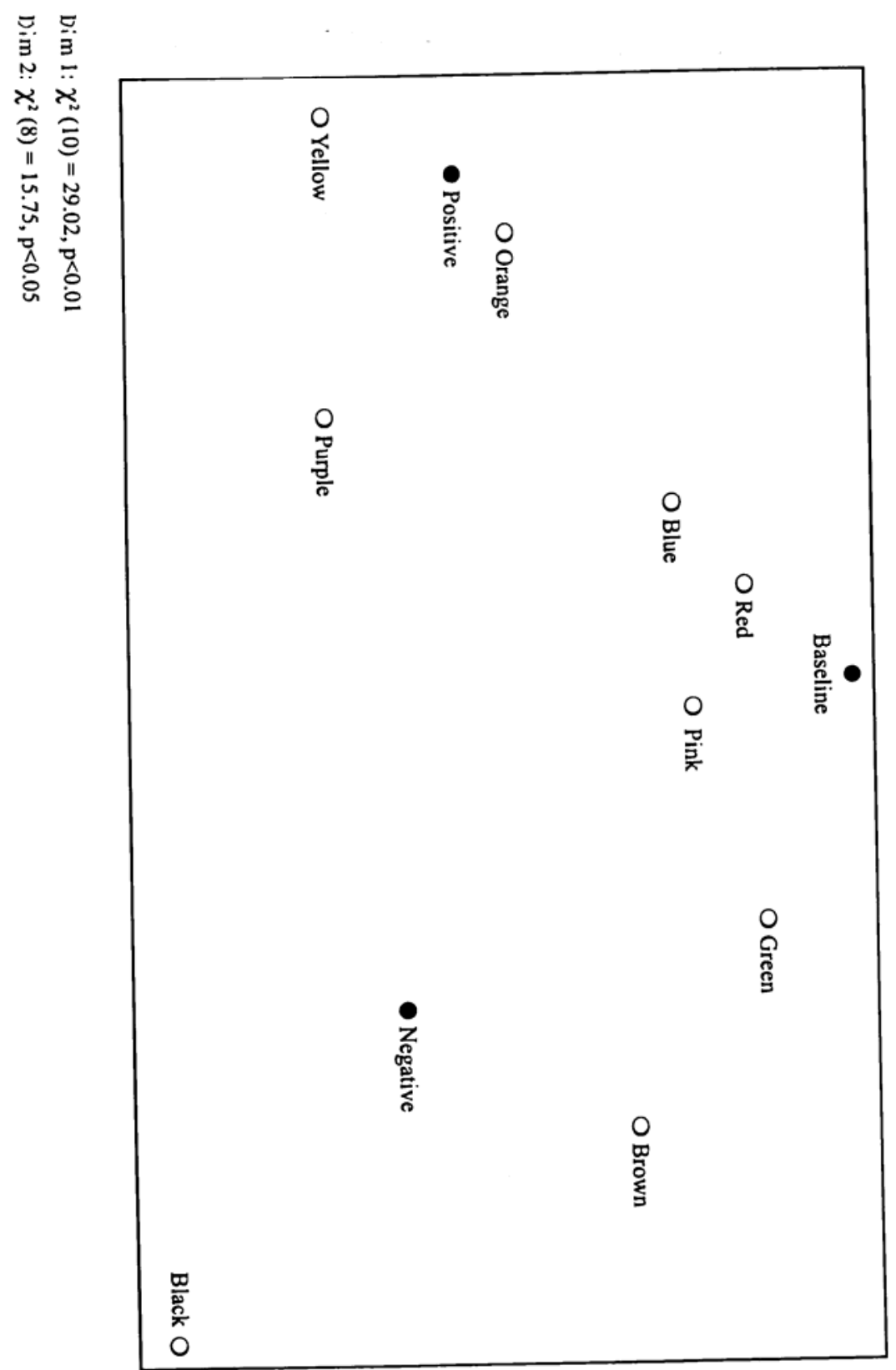

Plot 2: Colour choices for each drawing type by the HS group. 


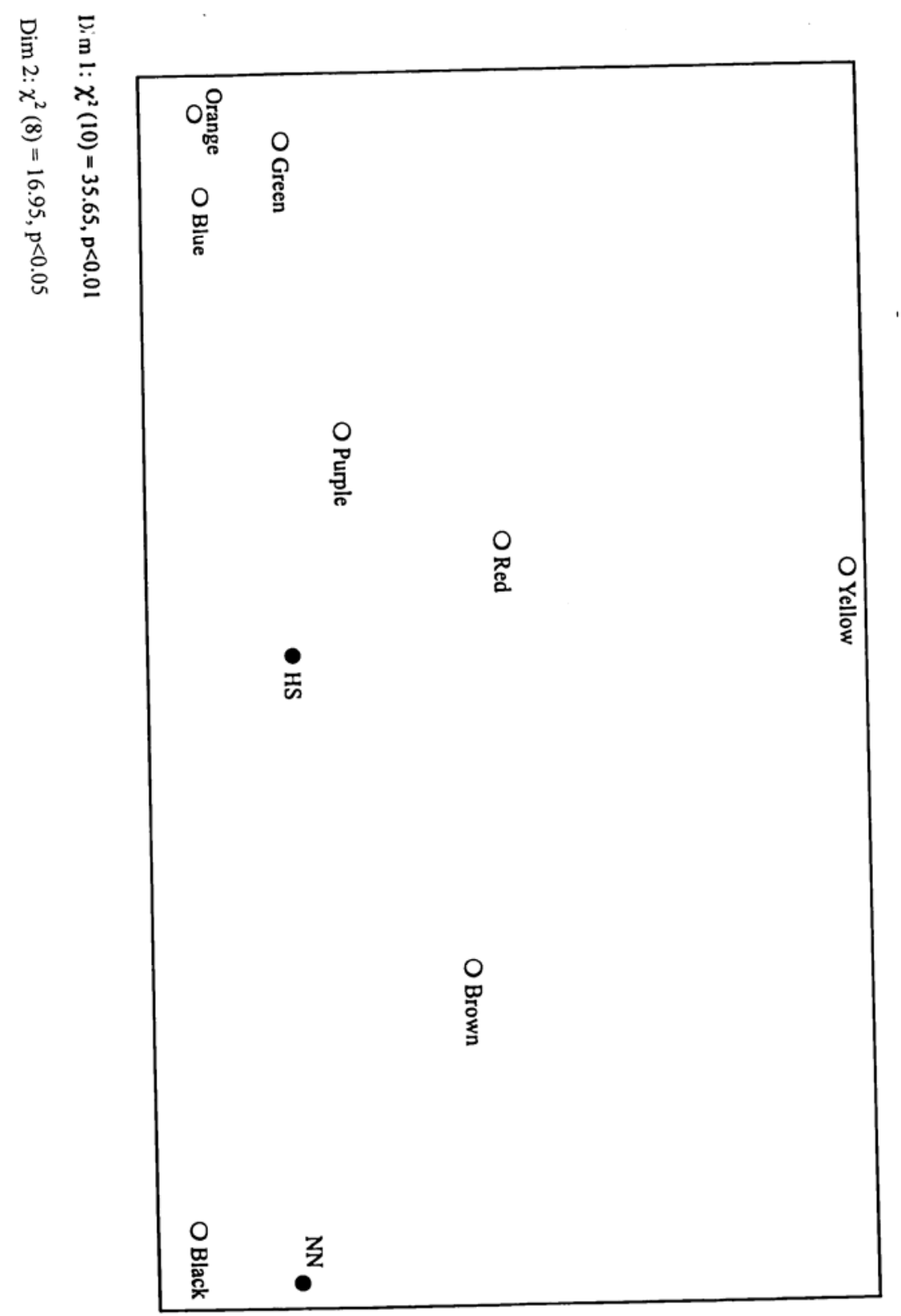

Plot 3: Colour choices for the negative figures by the NN vs. HS groups. 